\title{
Relationship between patient-reported and objective measurements of hand function in patients with rheumatoid arthritis
}

\author{
S.M. Günay ${ }^{1}$, Z. Tuna ${ }^{2}$, D. Oskay ${ }^{2}$ \\ ${ }^{1}$ Uludag University Ataturk Rehabilitation Practice and Research Center, Bursa, Turkey; \\ ${ }^{2}$ Department of Physiotherapy and Rehabilitation, Faculty of Health Sciences, Gazi University Ankara, Turkey
}

\begin{abstract}
SUMMARY
Rheumatoid arthritis (RA) often results in impairments in upper extremities, especially in the small joints of hand. Involvement of hand brings limitations in activities of daily living. However, it is commonly observed that patient-reported functional status of hand does not always corresponds to their actual physical performance in the clinical setting. The aim of this pilot study is to investigate the relationship between patient self-reported and objectively measured hand functions in patients with RA.

Twenty-six patients $(51 \pm 13$ years) with RA diagnosis participated in the study. Hand grip and pinch (lateral, bipod, tripod) strengths were measured and Jebsen Hand Function Test (JHFT) was performed for objective functional performance. Duruöz Hand Index and Beck Depression Inventory - Turkish version were completed by patients.

Grip and all three-pinch strength results significantly correlated with Duruöz Hand Index scores $(\mathrm{p}<0.05)$. JHFT results except the sentence writing also correlated with the Duruöz scores $(\mathrm{p}<0.05)$.

Our results showed that self-reported outcome scales might be used for determining functional level of hand in patients with RA in rheumatology practice. Objective quantitative functional tests are the best methods in evaluating functional level of hand, but require valid and reliable equipment with accurate calibration. Therefore, in case of unavailability of objective assessment tools, patient-reported scales may also reflect the real status of hand functions.
\end{abstract}

Key words: Hand function; dexterity; rheumatoid arthritis; functional assessment.

\section{INTRODUCTION}

heumatoid arthritis (RA) is a disease that causes limitations to activities of daily living. Social participations and emotional responses might be affected during the chronic process of the disease $(1,2)$. Functional measurements take an important place in assessing this patient group, which experiences dysfunction as a result of physical and mental impairments (3).

Involvement of wrist and fingers in RA might result in impairments in the functional use of the hand. Hand functions include components such as joint structures, mobility, muscle strength, and coordination. Hand functions bear a critical importance in the independence of the individual due to the fact that using hands is required in numerous daily life activities (4). Phys- iotherapists need to make right choices from among various assessment tools for evaluating hand dysfunction. Among these tools, some are performance-based and are conducted by the therapist, others include questionnaires which are scored by patients themselves. Performance-based assessments provide first hand objective data about patients' hand functions; however, they are time-consuming and generally require various equipment. On the other hand, patient-reported questionnaires can be performed easily, but they provide subjective information since the evaluations are influenced by the patient perceptions. Although the functional measurements carried out by clinicians produce objective results, it was observed that these measurements might not match with the functional conditions perceived by patients. Eurenius $\overline{\text { Corresponding author }}$

Zeynep Tuna

Department of Physiotherapy and Rehabilitation, Faculty of Health

Sciences, Gazi University Ankara, Turkey

E-mail: zeyneptuna6@yahoo.com 
et al. noted the difference between physical activity and physical adaptation levels defined by the patients and assessed by the clinicians (1). For this reason, it is not clear how far patients' self-assessments overlap with the clinical findings and whether they provide accurate information (1). In addition, subjective and objective results in patients with RA do not always match and psychological factors also contribute to clinical representation. Therefore, patientreported assessments may not accurately report the patient's actual disease course (5).

The physical functions that are affected in daily life from the perspective of RA patients and how these functions were perceived by the patients were investigated by Tuominen et al. (6), who suggested that patient-reported parameters believed to be a reason for disability need to be measured in order to define functional disability in patients with RA. Furthermore, they concluded that patients' opinions should be considered in functional assessments.

Various tools that objectively and subjectively evaluate the hand functions have been defined in literature (7) and some of them were conducted on RA patients (8, 9). However, to the best of our knowledge, the consistency between objective and subjective measurements was not analysed. The objective of our study is to investigate the relationship between patient-reported functional levels and objective functional performance related to the hand functions in RA patients.

Thus, whether or not the disability levels perceived by patients reflect the actual condition would be established and become a guide for assessment and treatment in hand rehabilitation.

\section{MATERIALS AND METHODS}

\section{Participants}

This study was conducted at the Department of Rheumatology at the Atatürk Rehabilitation Application and Research Centre of Uludag University, Bursa, Turkey. RA patients who are regularly followed in the Rheumatology Outpatient Clinic with
Table I - Age, disease duration, grip endurance of dominant hand, $\mathrm{DHI}$ and $\mathrm{BDI}$ results of patients.

\begin{tabular}{|l|c|c|}
\hline & Median & Range \\
\hline Age (years) & 57 & $24-74$ \\
\hline $\begin{array}{l}\text { Duration of disease } \\
\text { (months) }\end{array}$ & 96 & $24-360$ \\
\hline Grip endurance (sec) & 55.3 & $15.4-191.3$ \\
\hline DHI & 19 & $0-53$ \\
\hline BDI & 9 & $0-43$ \\
\hline
\end{tabular}

DHI: Duruöz Hand Index; BDI: Beck Depression Inventory.

an age range of 20 to 65 years were included in the study. The inclusion criteria were the following: the diagnosis of RA at least 1 year prior to the study and no history of any upper extremity surgery. Patients were excluded from the study if they had the following: congenital malformations in upper extremity, a change in the medical treatment in the last three months, a significant change in disease activity in the last week that could be proven by laboratory or clinical findings, other systemic diseases, and cognitive problems that would prevent their participating in assessments. The participants were fully informed and provided their informed consent.

\section{Objective measurements}

Grip strength, grip endurance, and pinch strengths (bipod, tripod, lateral) were measured in order to objectively assess the functional condition of the hand. All the strength and endurance measurements were carried out using the standard test protocol recommended by the American Society of Hand Therapists.

During the testing, patients were in sitting position on a chair with back support, the shoulder was in adduction, the elbow was in $90^{\circ}$ flexion, and the wrist was in neutral position (10). Grip strength was measured with the Jamar Plus electronic hand dynamometer. Following the estimation of $1 / 3$ of maximal grip strength, grip endurance was recorded as the length of time the patient kept this predetermined value (11). Bipod, tripod and lateral pinch grip strength were measured with the Jamar 
Hydraulic pinch gauge (12). The measurements were repeated 3 times and their averages were calculated and were recorded in kilograms (kg).

\section{Subjective measurements}

Duruoz Hand Index (DHI) and Beck Depression Inventory (BDI) were used for the subjective assessment.

DHI is a functional evaluation scale, which was developed specifically for RA in 1996 (13). It comprises 18 items that evaluate hand and wrist activities. In this index, patients score their activities from 0 to 5 , and the total score ranges between 0 and 90 . Functional activity increases along with the rise in the score.

BDI is a questionnaire developed for the assessment of anxiety and depression and is comprised of 21 questions. BDI was used for evaluation of depression in patients with RA (14-16). The validity and reliability of the BDI scale's Turkish version have already been shown as satisfactory (17). The BDI total score determines the level of depression and a score above 30 points to severe depression (2).

\section{Statistical analysis}

SPSS Inc. 15.0 software package was used for the statistical analysis of the study data.
Descriptive results were given as median (range) as the data were not normally distributed.

Correlations between patients' grip strength with their DHI and BDI scores were assessed with Spearman's correlation analysis. A $p<0.05$ was accepted as statistically significant.

\section{RESULTS}

A total of 30 patients were invited to the study. Four patients that did not fulfil the inclusion criteria were excluded and analyses were carried out for 26 patients $(24 \mathrm{fe}$ males, 2 males) are shown in Table I.

Age, disease duration, grip endurance, DHI and BDI results are The median and range of grip and pinch strength are given in Table II. DHI scores were significantly correlated with disease duration and all objective outcomes of hand functions $(p<0.01)$ (Table III). BDI scores were significantly correlated with disease duration and objective functional results except for gross, bipod and lateral pinch strength $(\mathrm{p}<0.05)$ (Table III).

It is worth noting that a significantly good correlation was observed between DHI and BDI scores (rho: 0.797; $\mathrm{p}<0.001$ ) (data not shown).

Table II - Gross and pinch (bipod, tripod and lateral) strengths of right and left hand of patients.

\begin{tabular}{|l|c|c|}
\hline & Right [Median (range)] & Left [Median (range)] \\
\hline Gross $(\mathrm{kg})$ & $16.7(2.6-41.2)$ & $19.8(3.4-41.4)$ \\
\hline Lateral $(\mathrm{kg})$ & $5.6(1-9)$ & $5(1-7)$ \\
\hline Bipod $(\mathrm{kg})$ & $4.7(2-10.2)$ & $4(2-10)$ \\
\hline Tripod $(\mathrm{kg})$ & $5(1.8-7)$ & $4.6(1-8)$ \\
\hline
\end{tabular}

Table III - Results of Spearman's correlation analysis between DHI, BDI and hand function results.

\begin{tabular}{|l|l|c|c|c|c|c|c|c|c|c|c|}
\hline & & $\begin{array}{c}\text { Disease } \\
\text { duration } \\
\text { (months) }\end{array}$ & GrossR & GrossL & Endurance & BipodR & bipodL & LateralR & LateralL & TripodR & TripodL \\
\hline \multirow{2}{*}{$\mathrm{DHI}$} & rho & 0.498 & -0.609 & -0.511 & -0.652 & -0.627 & -0.549 & -0.684 & -0.536 & -0.665 & -0.713 \\
\cline { 2 - 13 } & $\mathrm{p}$ & 0.010 & 0.001 & 0.008 & 0.000 & 0.001 & 0.004 & 0.000 & 0.005 & 0.000 & 0.000 \\
\hline \multirow{2}{*}{$\mathrm{BDI}$} & rho & 0.448 & -0.386 & -0.351 & -0.616 & -0.312 & -0.428 & -0.307 & -0.420 & -0.412 & -0.531 \\
\cline { 2 - 12 } & $\mathrm{p}$ & 0.025 & 0.057 & 0.085 & 0.001 & 0.129 & 0.033 & 0.136 & 0.037 & 0.041 & 0.006 \\
\hline
\end{tabular}

DHI: Duruöz Hand Index; BDI: Beck Depression Inventory. 


\section{DISCUSSION}

AND CONCLUSIONS

This study showed that patient-reported functional status of the hand is related to objectively measured hand functions in patients with RA. Noticeably, the disability level reported by the patients was related to their depression level. Although our study had a low number of participants, significant correlations were seen even in such a small population.

There are some other studies in literature that corroborate our results $(2,9,18,19)$. Dedeoglu et al. evaluated 102 patients with RA and showed a strong correlation between the DHI and pinch strengths (8). Similarly, Ozeri et al. reported that grip strength and range of motion of the joint were correlated with DHI and Hand Functional Index (20). Bircan et al. analysed the relationship between Grip Ability Test and disease activity and showed a significant correlation between the Grip Ability Test and the DHI (21). The DHI, as seen in these studies, is the most frequently used questionnaire to assess the patient-reported disability level in RA.

However, there are some other results that do not agree with those of our study. Kauranenet al. analysed the motor performance of the hand in patients with RA and investigated the correlation with the Keitel Functional Test (KFT) (22). No correlation was reported between objective motor performance tests and Keitel Functional Test (KFT) scores, grip strength, disease duration, and the number of involved joints. However, although the KFT was utilised for subjective assessment, it is actually a test that is based on the observations of the clinician (23). Therefore, the subjective characteristic of this test does not result from the perceptions of the patient, but from the observations of clinician.

The most disconcerting result of this study is the significant and strong correlation between depression and patient-reported disability levels. Previous studies showed that functional limitations in patients with RA are related not only to physical parameters but also to cognitive impairment (24). Katz et al. also claimed that decreased physical activity level results in increased dysfunction. Functional decline may result in patient's self-efficacy and thus in depressive symptoms (25). In a study focusing on the influence of psychological activity on function, it was shown that poor performance in reaction time is related to depression in RA patients compared to healthy individuals (2). Therefore, assessing the depressive status of patient may help the clinician to make an accurate assessment of functional and disability level.

There are some other studies showing that emotional and psychological status may negatively affect the functional level in RA $(2,26)$. Thus, the emotional and psychological status of the patients should also be taken into consideration during assessments. In our study, a strong positive correlation was also observed between depression scores and patient-reported disability. It can be concluded that the function is not affected only by the impairment in body structures but also by individual and environmental factors.

Since the aim of this study was to investigate the relation between patient-perceived and performance-based functional status, disease activity was not taken into consideration. Future studies comparing patients with different levels of disease activity could reveal the role of disease activity on the perceived functional condition.

To conclude, objective and subjective assessment tools may be appropriate, independently from each other, for functional hand assessment in patients with RA. Moreover, depressive status should always be taken into account in order to determine the patient's disability level accurately.

\section{Conflict of interest}

The authors declare no conflict of interest.

\section{REFERENCES}

1. Eurenius E, Stenström CH. Physical activity, physical fitness and general health perception among individuals with rheumatoid arthritis. Arthritis Rheum. 2005; 53: 48-55.

2. Todorovic ST, Hanna F, Boskovic K, et al. 
Motor ability and emotions in rheumatoid arthritis patients. J Neurol Neurophysiol. 2012; 3: 137.

3. Piva SR, Almeida GJ, Wasko MC. Association of physical function and physical activity in women with rheumatoid arthritis. Arthritis Care Res (Hoboken). 2010; 62: 1144-51.

4. Eberhardt K, Sandqvist G, Geborek P. Hand function tests are important and sensitive tools for assessment of treatment response in patients with rheumatoid arthritis. Scand J Rheumatol 2008; 37: 109-12.

5. Shin SY, Katz P, Julian L. Relationship between perceived cognitive dysfunction and objective neuropsychological performance in persons with rheumatoid arthritis. Arthritis Care Res (Hoboken). 2013; 65: 481-6.

6. Tuominen R, Tuominen S, Suominen C, et al. Perceived functional disabilities among rheumatoid arthritis patients. Rheumatol Int. 2010; 30: 643-9.

7. Rallon CR, Chen CC. Relationship between performance-based and self-reported assessment of hand function. Am J Occup Ther. 2008; 62: 574-9.

8. Dedeoglu M, Gafuroglu U, Yilmaz O, Bodur H. The Relationship between hand grip and pinch strengths and disease activity, articular damage, pain, and disability in patients with rheumatoid arthritis. Turk J Rheumatol. 2013; 28: 69-77.

9. Groarke A, Curtis R, Coughlan R, Gsel A. The role of perceived and actual disease status in adjustment to rheumatoid arthritis. Rheumatology (Oxford). 2004; 43: 1142-9.

10. Bansal N. Hand grip strength: normative data for young adults. Indian $\mathrm{J}$ Physiother Occup Ther. 2008; 2: 29-33.

11. Bandyopadhyay A. Body composition and hand grip strength in male brick-field workers. Malays J Med Sci. 2008; 15: 31-6.

12. Mathiowetz V, Weber K, Volland G, Kashman N. Reliability and validity of grip and pinch strength evaluations. J Hand Surg Am. 1984; 9: 222-6.

13. Duruoz MT, Poiraudeau S, Fermanian J, et al. Development and validation of a rheumatoid hand functional disability scale that assesses functional handicap. J Rheumatol. 1996; 23: 1167-72.

14. Krug HE, Woods SR, Mahowald ML. The importance of identifying depression in patients with rheumatoid arthritis: evaluation of the beck depression inventory. J Clin Rheumatol. 1997; 3: 248-57.
15. Melikoglu MA, Melikoglu M. The relationship between disease activity and depression in patients with Behcet disease and rheumatoid arthritis. Rheumatol Int. 2010; 30: 941-6.

16. Imran MY, Saira Khan EA, Ahmad NM, et al. Depression in rheumatoid arthritis and its relation to disease activity. Pak J Med Sci. 2015; 31: 393-7.

17. Sariyildiz MA, Batmaz I, Bozkurt M, et al. Sleep quality in rheumatoid arthritis: relationship between the disease severity, depression, functional status and the quality of life. J Clin Med Res. 2014; 6: 44-52.

18. Adams J, Burridge J, Mullee M, et al. Correlation between upper limb functional ability and structural hand impairment in an early rheumatoid population. Clin Rehabil. 2004; 18 : 405-13.

19. Akkaya N, Başakçı B, Erel S, et al. Are functional assessment questionnaires related with hand function tests in patients with nerve injury at the level of wrist and in patients with tendon injury/fracture at the level of fingers? Türk Fiz Tip Rehab Derg. 2013; 59: 112-6.

20. Özeri Z, Çakıt BD, Taşkın S, et al. The relationships among functional impairment, disability and articular damage in rheumatoid hand. J PMR Sci. 2008; 2: 53-8.

21. Bircan C, Gündüz EN, Tekgül A, et al. Grip ability test in rheumatoid arthritis patients: Relationship with disease activity and hand-specific self-report questionnaires. Arch Rheumatol. $2014 ; 29$ : 160-6.

22. Kauranen K, Vuotikka P, Hakala M. Motor performance of the hand in patients with rheumatoid arthritis. Ann Rheum Dis. 2000; 59: 812-6.

23. Holm B, Jacobsen S, Skjodt H, et al. Keitel functional test for patients with rheumatoid arthritis: translation, reliability, validity, and responsiveness. Phys Ther. 2008; 88: 664-78.

24. Shin SY, Julian L, Katz P. The relationship between cognitive function and physical function in rheumatoid arthritis. J Rheumatol. 2013; 40: 236-43.

25. Katz PP, Yelin EH. The development of depressive symptoms among women with rheumatoid arthritis. The role of function. Arthritis Rheum. 1995; 38: 49-56.

26. Dickens C, Creed F. The burden of depression in patients with rheumatoid arthritis. Rheumatology (Oxford). 2001; 40: 1327-30. 